\title{
Potential for Improving Description of Bovine Udder Health Status by Combined Analysis of Milk Parameters
}

\author{
K. H. M. N. Sloth, ${ }^{\star}$ N. C. Friggens, ${ }^{*}$ P. Løvendahl, $\dagger$ \\ P. H. Andersen, $\ddagger$ J. Jensen, $†$ and K. L. Ingvartsen* \\ ${ }^{*}$ Department of Animal Health and Welfare and †Department of Animal Breeding and Genetics, \\ Danish Institute of Agricultural Sciences, \\ Research Center Foulum, P.O. Box 50, DK-8830 Tjele, Denmark \\ ‡Department of Clinical Studies, \\ Royal Veterinary and Agricultural University, \\ Dyrlægevej 48, DK-1870 Frederiksberg C, Denmark
}

\section{ABSTRACT}

The objective of this study was to assess the potential of a stepwise multivariate procedure to quantify cowlevel udder health based on eight milk parameters: milk yield, protein percentage, fat percentage, lactose percentage, citrate percentage, somatic cell count (SCC), and two electrical conductivity parameters. The data were collected in one research herd and included 821 cow-level observations. In addition to milk parameters, disease recordings and bacteriology on quarter milk samples every eighth week throughout lactation were included. A multivariate mixed model was applied to the milk parameters in a healthy subset to adjust for the following systematic factors: total mixed ration (TMR) energy density, breed-line combination, parity, stage of lactation, and season. The proportion of variance accounted for by the mixed model ranged from 0.14 to 0.82 depending on milk parameter. The adjustments estimated in the healthy subset were applied to the whole dataset, including observations pertaining to nonhealthy cows. Combined description of the adjusted variation in the milk parameters was performed with a principal component analysis. The first principal component (Prin1) described 30\% of the adjusted variation and was interpreted as being the main consequences of mastitis. Finally, cluster analysis based on Prin1 separated the observations into nine clusters, which were strongly associated with udder health in terms of increasing clinical and subclinical mastitis with increasing level of Prin1. It was concluded that a multivariate approach to assess udder health from milk parameters has the potential to substantially improve description of udder health.

Received May 13, 2002.

Accepted September 12, 2002.

Corresponding author: K. H. M. N. Sloth; e-mail: karenh.sloth@ agrsci.dk.
(Key words: bovine udder health, milk parameter, multivariate analysis)

Abbreviation key: Cavg = average electrical conductivity across quarters within cow, Cdiff $=$ maximum difference in electrical conductivity between quarters within cow, DH = Danish Holstein, DR = Danish Red, Jer $=$ Jersey, PCA $=$ Principal component analysis, Prin1 = first principal component, Prin2 = second principal component, Prin3 = third principal component.

\section{INTRODUCTION}

Combined analysis of milk yield, milk composition, and clinical data has been proposed by Hamann and Krömker (1997) to improve both the extent and quality of information regarding udder health. The rationale for this is that mastitis has a range of effects on the milk produced. The inflammatory reaction caused by infections in the mammary tissue is most commonly measured as increases in SCC in milk (Cullen, 1966; Dohoo and Meek, 1982; Erskine, 2001). Other responses to mastitis are reduced milk yield and changes in the chemical composition of the milk caused by cellular damage and increased permeability in membranes in the mammary tissue (Kitchen, 1981). A number of investigations have described increasing responses in milk parameters at quarter-level with increasing severity of the mastitis (Wheelock et al., 1966; Ashworth et al., 1967; Oshima and Fuse, 1981; Woolford, 1985; Hortet et al., 1999). This suggests that combined analysis may not only have the potential for improved prediction of diseased animals but possibly also improved quantification of the severity of the disease.

Hamann and Krömker (1997) suggested that quarter-based measurements and analysis would be necessary to eliminate dilution of changes by milk from uninfected quarters and interfering systematic variation. However, even though the fact that cow-level milk parameters are affected by additional complexity, cow- 
level SCC in milk has been established as the cornerstone in monitoring udder health in mastitis control programs (Schukken and Kremer, 1996; Erskine, 2001). Recent developments in milking technology and laboratory equipment offer the opportunity to measure lactose, citrate, and electrical conductivity in milk on a routine basis in addition to milk yield, fat, protein, and SCC. These cow-level milk parameters are not only affected by the udder health of the cow but also, in various ways, by systematic factors like breed, parity, stage of lactation, and season (Dohoo and Meek, 1982; Kaufmann and Hagemeister, 1987; Hellander et al., 1989; Hamann and Zeconni, 1998). Provided that a combined analysis of cow-level milk parameters handles these systematic factors appropriately, it should, to a large extent, overcome the limitations of single cowlevel indicators given that inclusion of milk composition along with milk yield will take into account the relations between changes in the concentration of milk components, the actual milk secreted (Schultz, 1977), and the influence from number of quarters infected per cow (Natzke et al., 1972).

The overall objective of this study was to assess the potential of a stepwise multivariate procedure to quantify udder health based on several cow-level milk parameters. The necessary steps in this procedure were to achieve, first, a satisfactory adjustment for systematic factors, second, a combined description of the adjusted variation, and, third, a classification based on the described variation in the milk parameters, which related to independently assessed udder health.

\section{MATERIALS AND METHODS}

\section{Experimental Animals and Data Collection}

The data originated from a 5 -yr experiment carried out at the research farm Ammitsbøl Skovgaard, Denmark. Detailed information about the experiment and the design is published elsewhere (Nielsen et al., 2003). Data were collected from January 1, 1997, to October 1,2001 . The research farm had a capacity of 110 cows per year. The cows in the experiment belonged to one of two genetic lines within each of the three breeds: Danish Red (DR, $\mathrm{n}=108)$, Danish Holstein $(\mathbf{D H}, \mathrm{n}=$ 131), and Jerseys (Jer, $\mathrm{n}=83$ ). The lines for $\mathrm{DH}$ and DR were selected for either milk yield or dual purpose (milk and meat), while the lines for Jer were either American or Danish Jersey. The cows were randomly assigned to one TMR with either low (12.88 MJ DE/kg $\mathrm{DM})$ or normal (13.55 MJ DE/kg DM) energy density during the lactation period. In the dry period, all cows were fed the low energy density TMR. Cows remained in the experiment through consecutive lactations during which they stayed on the same feeding treatment.
The dataset included date of registration, animal identification, feeding ration, breed, genetic line, parity, stage of lactation (days from calving), and milking (a.m. or p.m.). From each milking cow-level milk yield, milk composition, SCC, and quarter-level conductivity were included. Furthermore, the dataset did include disease records and results from bacteriological examinations of quarter foremilk samples taken out every eighth week from calving to drying off.

\section{Milk Parameters}

The eight milk parameters used in this study were milk yield, fat percentage, protein percentage, lactose percentage, citrate percentage, composite SCC (1000 cells $/ \mathrm{ml}$ ), and two conductivity parameters. Milk yield was measured in kilograms of milk (Milk Meter, SAC). A proportional milk sample was taken out during each milking (Milk Meter, SAC) and stored at $2{ }^{\circ} \mathrm{C}$ without use of preservatives. The average time lag from sampling to analysis was $1.9 \mathrm{~d}$. Milk composition and SCC were analyzed using a CombiFoss 4000 (FossElectric, Hillerød, Denmark). Electrical conductivity in the milk $(\mathrm{mS} / \mathrm{cm})$ was measured at quarter-level every $2 \mathrm{~s}$ during a milking by sensors built into the milk liners.

\section{Disease Records and Udder Health Surveillance Scheme}

Disease diagnoses and treatments were recorded. The technical staff at the research farm conducted during their daily handling of the animals a close control with the health status. When disease was suspected or detected, veterinary assistance was obtained.

An udder health surveillance scheme was applied, in which quarter foremilk samples were taken out aseptically by veterinarians or milk quality technicians every eighth week, starting within the first week after calving and ending at drying off. These quarter milk samples were analyzed at a certified mastitis laboratory to obtain bacteriological diagnoses of possible IMI.

In the study, cow-level clinical mastitis was defined as recorded veterinary treatments for mastitis in at least one-quarter within cow. Likewise, cow-level subclinical mastitis was defined as at least one bacteriological positive diagnose within cow in the udder health surveillance scheme. In addition, for calculation of quarter-level disease statistics, the actual number of infected quarters was included.

\section{Data Manipulation}

A quarter-level variable for electrical conductivity was calculated as an average of the 20 highest measure- 
ments per quarter per milking as described by Nielen et al. (1993). Before the statistical analysis, electrical conductivity at quarter-level was reformulated into two composite cow-level variables, Cdiff and Cavg. Cdiff was calculated as the difference between the quarter with the highest and the quarter with the lowest conductivity within a cow at a given milking. Cavg represented the mean conductivity of all quarters within a cow at a given milking.

Data on milk parameters from five intervals in lactation, each of 10-d duration, were selected. These five intervals were placed equally around the time of quarter foremilk sampling in the udder health surveillance scheme (interval 1: 1 to $10 \mathrm{~d}$ from calving, interval 2: 61 to $70 \mathrm{~d}$ from calving, interval 3: 124 to $133 \mathrm{~d}$ from calving, interval 4: 187 to $196 \mathrm{~d}$ from calving, and interval 5: 251 to $260 \mathrm{~d}$ from calving).

SCC and Cdiff were $\log _{10}$ transformed before analysis, and individual averages of all milk parameters were calculated across each interval in lactation. For milk yield, simple a.m. and p.m. averages were calculated and then summarized. For milk composition, including SCC, a.m., and p.m. averages across an interval were first calculated weighted according to the measured milk yield at a given milking. Interval averages were then produced as the average of a.m. and p.m. averages weighted according to the average a.m. and p.m. milk yield. For the conductivity parameters, simple averages were first calculated for a.m. and p.m. milkings across the interval and next across these.

\section{Definition of a Healthy Data Subset}

A definition of a healthy data subset was needed to avoid interference from variation caused by differences in udder health when adjusting milk parameters for systematic factors. The healthy subset was defined as cows with negative bacteriological quarter foremilk samples on two consecutive samplings in the udder health surveillance scheme, no clinical cases of mastitis between the two samplings and no records of other diseases in the selected intervals in lactation. The reason for not including cow-level SCC in the definition was to allow the SCC to be included solely as a response variable. Full $(n=527)$ and partial $(n=19)$ observations (single missing parameters of milk composition or electrical conductivity) qualified to enter the healthy data subset.

\section{Statistical Methods}

SAS version 8.e (SAS Inst. Inc., Cary, NC) was used for all the statistical analyses.

A multivariate mixed model of systematic and random factors was chosen to utilize a common covariance structure and find the best-fitting common model to predict values for healthy cows of all the milk parameters. The systematic factors included were TMR energy density, breed, genetic line, parity, stage of lactation via the selected intervals in lactation, and season. Season represented a combined season-year effect defined quarterly within year starting with the January to March quarter, 1997. A first base model included all main effects and the two-way interaction term between breed and line. Cow was fitted as random effect and cow within parity and interval in lactation as repeated effect with an unstructured covariance matrix assumed. Option for no intercept was set. Forward selection $(P<0.25)$ of possible two-way interaction terms except with season was then performed to make a second base model followed by stepwise backward elimination of nonsignificant terms $(P<0.05)$. The final overall model was as follows:

$$
\begin{aligned}
& \mathrm{Y}_{\mathrm{ijk} k m n o}^{\mathrm{r}}=\mu^{\mathrm{r}}+\alpha_{\mathrm{i}}^{\mathrm{r}}+\beta_{\mathrm{j}}^{\mathrm{r}}+\tau_{\mathrm{k}}^{\mathrm{r}}+\lambda_{\mathrm{l}}^{\mathrm{r}}+\delta_{\mathrm{m}}^{\mathrm{r}}+\kappa_{\mathrm{n}}^{\mathrm{r}}+\beta^{\mathrm{r}} \tau_{\mathrm{jk}}^{\mathrm{r}}+\beta^{\mathrm{r}} \lambda_{\mathrm{j} 1}^{\mathrm{r}} \\
& +\beta^{\mathrm{r}} \delta_{\mathrm{jm}}^{\mathrm{r}}+\mathrm{A}_{\mathrm{o}}^{\mathrm{r}}+\varepsilon_{\mathrm{ijklmno}}^{\mathrm{r}} \text {, }
\end{aligned}
$$

where

$\mathrm{r}=$ specific to the rth milk parameter (milk yield, fat percentage, protein percentage, lactose percentage, citrate percentage, $\log _{10} \mathrm{SCC}$, $\log _{10}$ Cdiff, Cavg)

$\mathrm{Y}_{\mathrm{ijklmno}}^{\mathrm{r}}=$ observed average value of the rth milk parameter within effect $t_{\mathrm{jjklmn}}$ and $\mathrm{cow}_{\mathrm{o}}$

$\mu^{\mathrm{r}}=$ overall average of the rth milk parameter

$\alpha_{\mathrm{i}}^{\mathrm{r}}=$ fixed effect of TMR energy density $\mathrm{i}, \mathrm{i}=$ \{low, normal\}

$\beta_{\mathrm{j}}^{\mathrm{r}}=$ fixed effect of breed $\mathrm{j}, \mathrm{j}=\{\mathrm{DR}, \mathrm{DH}, \mathrm{Jer}\}$

$\tau_{\mathrm{k}}^{\mathrm{r}}=$ fixed effect of genetic line $\mathrm{k}, \mathrm{k}=\{1,2\}$

$\lambda_{1}^{\mathrm{r}}=$ fixed effect of parity $l, l=\{1,2,3,4\}$

$\delta_{\mathrm{m}}^{\mathrm{r}}=$ fixed effect of interval in lactation $\mathrm{m}, \mathrm{m}=\{1$, $2,3,4,5\}$

$\kappa_{\mathrm{n}}^{\mathrm{r}}=$ fixed effect of season within year, $\mathrm{n}=\{1,2$, 19\}

$\mathrm{A}_{0}^{\mathrm{r}}=$ random effect of cow $0, \mathrm{~A}_{0}^{\mathrm{r}} \sim \mathrm{N}\left(0, \sigma_{\mathrm{rA}}^{2}\right)$

$\varepsilon_{\mathrm{ijklmno}}^{\mathrm{r}}=$ residual variation

$\varepsilon_{\mathrm{ijklmno}}=\left(\varepsilon_{\mathrm{ijklmno}}^{1}, \ldots . . ., \varepsilon_{\mathrm{ijklmno}}^{8}\right) \sim \mathrm{N}_{8}\left(0, \sigma_{\varepsilon}^{2}\right)$,

where $\sigma_{\mathrm{A}}$ and $\sigma_{\varepsilon}$ were unstructured $8 \times 8$ covariance matrices.

Evaluation of model performance was performed on residuals with production of quartile-quartile plots and plots of residuals against predicted values. Proportion of variance accounted for by the mixed model was calculated as the difference in residual variance between the null-model (only random effects) and the final model divided with the residual variance in the null-model. 
The mixed model provided coefficients to estimate predicted healthy levels of the parameters in milk. These estimated predicted values were subtracted from observed values in the full data set, giving adjusted values for each milk parameter representing the nonsystematic variation (udder health variation, unaccounted systematic variation, measurement errors). In total, 821 full observations from 168 cows with adjusted values were available for further analyses.

Principal component analysis (PCA) was used to describe the variation in the full dataset of adjusted values. The PCA was based on the correlation matrix to give equal weighting to parameters of differing variability. A univariate cluster analysis was then performed on the score values of the first principal component (Prin1) to separate the cows into different groups. Two hierarchical methods were used, the centroid method and Ward's method, to identify the minimum number of clusters necessary. The final cluster analysis was performed using a nonhierarchical method to optimize the cluster procedure as recommended by Sharma (1996). Finally, the clusters were renamed in such a way that the average of Prin1 was increasing with increasing cluster number.

To characterize the animals and examine udder health within individual clusters of observations, several key figures on udder health, distributions of certain risk factors and relative milk parameter performance were calculated. Incidences of clinical mastitis overall and within clusters were calculated as the actual rates of clinical mastitis within a $30-d$ period prior to the end of an interval in lactation as quarter cases per 30 quarter days at risk and cow cases per 30 cow days at risk. An 8-d lag time not at risk after a clinical mastitis incident was subtracted in the calculations of days at risk to differentiate between already recorded cases and the occurrence of new cases of clinical mastitis, as recommended by IDF (1997). Prevalences of subclinical mastitis overall and within clusters were calculated as number of quarters with positive diagnoses in the udder health surveillance scheme per total number of quarters examined and as number of cows with positive diagnoses per total number of cows examined. Simple correlations between cluster number, incidences of clinical mastitis, and prevalences of subclinical mastitis were calculated to judge the significance of the final output of the analysis. Frequency distributions of specific diagnoses in the udder health surveillance scheme, systematic factors, and average observed levels of milk parameters relative to estimated healthy levels with $95 \%$ confidence limits were calculated as well.
Table 1. Distribution of cow-level observations $(n=821)$ in relation to the systematic factors: TMR energy density, genetic line within breed, parity, and interval in lactation.

\begin{tabular}{lllr}
\hline Systematic factor & Level & $\mathrm{N}$ & $\%$ \\
\hline TMR energy density & Low & 446 & 54.3 \\
& Normal & 375 & 45.7 \\
Breed $\times$ line & $\mathrm{DR}^{1} \times$ line 1 & 118 & 14.4 \\
& $\mathrm{DR}^{1} \times$ line 2 & 138 & 16.8 \\
& $\mathrm{DH}^{2} \times$ line 1 & 159 & 19.4 \\
& $\mathrm{DH}^{2} \times$ line 2 & 150 & 18.3 \\
& $\mathrm{Jer}^{3} \times$ line 1 & 70 & 8.5 \\
& $\mathrm{Jer}^{3} \times$ line 2 & 186 & 22.6 \\
Parity & 1 & 373 & 45.4 \\
& 2 & 321 & 39.1 \\
& 3 & 105 & 12.8 \\
Interval in lactation & 4 & 22 & 2.7 \\
& 1 to $10 \mathrm{~d}$ & 76 & 9.3 \\
& 61 to $70 \mathrm{~d}$ & 202 & 24.6 \\
& 124 to $133 \mathrm{~d}$ & 196 & 23.9 \\
& 187 to 196 d & 178 & 21.7 \\
& 251 to $260 \mathrm{~d}$ & 169 & 20.6 \\
\hline
\end{tabular}

${ }^{1} \mathrm{DR}=$ Danish Red.

${ }^{2} \mathrm{DH}=$ Danish Holstein

${ }^{3}$ Jer $=$ Jersey.

\section{RESULTS}

\section{Multivariate Mixed Model on Healthy Data Subset}

The distribution of observations in relation to systematic factors and summary statistics of un-transformed milk parameters are shown in Tables 1 and 2 .

The model performed satisfactorily for all eight milk parameters. Both quartile-quartile plots and plots of residuals against predicted values of the milk parameters indicated no lack of fit of the model used. The main effects (TMR energy density, breed, line, parity, interval in lactation, and season) and the interaction terms (breed*line, breed*parity, and breed*interval in lactation) included in the final model all had $P$-levels $<0.0001$. The proportion of variance accounted for by the model in milk parameters of the healthy subset is shown in Table 3. The fixed effects had a relatively large influence on fat percentage, protein percentage, and Cavg, medium influence on milk yield, lactose percentage, $\log _{10} \mathrm{SCC}$, and $\log _{10} \mathrm{Cdiff}$, and relatively low influence on the citrate percentage.

\section{Principal Component Analysis on Adjusted Values of the Full Dataset}

The first three principal components (Table 4) had eigenvalues greater than one. Together, they described $63 \%$ of the variation in the adjusted values of the milk parameters: Prin 1 , accounting for $30 \%$, the second principal component (Prin2) for 20\%, and the third principal component (Prin3) for 13\%. Score values for the principal components were generated for each observa- 
Table 2. Overall summary statistics of milk parameters in the defined healthy ${ }^{1}$ subset and the subset different from defined healthy.

\begin{tabular}{|c|c|c|c|c|c|c|}
\hline \multirow[b]{2}{*}{ Milk parameter } & \multicolumn{3}{|c|}{$\begin{array}{l}\text { Defined healthy subset } \\
\qquad(\mathrm{n}=520)\end{array}$} & \multicolumn{3}{|c|}{$\begin{array}{l}\text { Subset defined different from } \\
\text { healthy }(\mathrm{n}=301)\end{array}$} \\
\hline & Mean & Std. Dev. & Range & Mean & Std. Dev. & Range \\
\hline Milk yield, kg & 20.72 & 5.86 & 5.38 to 42.75 & 21.30 & 6.19 & 5.81 to 39.06 \\
\hline Fat, \% & 5.08 & 1.07 & 3.13 to 8.63 & 4.97 & 1.02 & 3.17 to 8.67 \\
\hline Protein, \% & 3.75 & 0.50 & 2.65 to 5.21 & 3.75 & 0.55 & 2.81 to 5.23 \\
\hline Lactose, \% & 4.73 & 0.22 & 3.27 to 5.23 & 4.74 & 0.20 & 4.05 to 5.19 \\
\hline Citrate, \% & 0.18 & 0.03 & 0.08 to 0.30 & 0.17 & 0.03 & 0.11 to 0.26 \\
\hline SCC, 1000 cells $/ \mathrm{ml}$ & 90.60 & 156.4 & 5.0 to 1666.0 & 348.76 & 573.0 & 11.0 to 5449.2 \\
\hline $\mathrm{Cdiff}^{2}, \mathrm{mS} / \mathrm{cm}$ & 0.64 & 0.52 & 0.13 to 4.51 & 1.07 & 1.06 & 0.14 to 7.60 \\
\hline $\mathrm{Cavg}^{3}, \mathrm{mS} / \mathrm{cm}$ & 4.81 & 0.73 & 3.27 to 8.13 & 4.98 & 0.68 & 3.42 to 7.09 \\
\hline
\end{tabular}

\footnotetext{
${ }^{1}$ Healthy definition: observations with negative bacteriological quarter foremilk samples on two consecutive samplings in the udder health surveillance scheme, no clinical cases of mastitis between the two samplings, and no records of other diseases in the selected intervals in lactation.

${ }^{2}$ Cdiff = Maximum difference in electrical conductivity between quarters within cow .

${ }^{3}$ Cavg $=$ Average electrical conductivity within cow
}

tion based on standardized values of original adjusted variables and the eigenvectors (weights) given in Table 4 for each observation. The loadings also given in Table 4 are simple correlations between the original and the new variables. A loading $>|0.5|$ may be used to indicate that an original variable is influential in forming the new variable (Sharma, 1996). Thus, Prin 1 could be described primarily as a contrast between on the one hand, milk yield and lactose percentage and on the other hand protein percentage $\log _{10} \mathrm{SCC}$, and $\log _{10}$ Cdiff. Prin2 mainly represented a contrast of fat and protein percentages vs. Cavg. Prin 3 was primarily dominated by the citrate percentage, although some contrasting was evident between Cavg, citrate and fat percentages vs. lactose percentage, $\log _{10} \mathrm{SCC}$, and $\log _{10}$ Cdiff.

\section{Cluster Analysis on the First Principal Component}

Plots of evaluation parameters generated from the hierarchical cluster analyses suggested that there were

Table 3. Variance reductions in milk parameter residuals in the healthy data subset by multivariate mixed model.

\begin{tabular}{|c|c|c|}
\hline Residual of & $\mathrm{N}$ & $\begin{array}{l}\text { Variance } \\
\text { reduction }\end{array}$ \\
\hline Milk yield, kg & 546 & 0.57 \\
\hline Fat $\%$ & 527 & 0.82 \\
\hline Protein \% & 527 & 0.79 \\
\hline Lactose \% & 527 & 0.48 \\
\hline Citrate \% & 527 & 0.14 \\
\hline $\log _{10} \mathrm{SCC},{ }^{1} 1000$ cells $/ \mathrm{ml}$ & 527 & 0.31 \\
\hline $\log _{10} \operatorname{Cdiff}^{2}, \mathrm{mS} / \mathrm{cm}$ & 539 & 0.31 \\
\hline Cavg, ${ }^{3} \mathrm{mS} / \mathrm{cm}$ & 539 & 0.68 \\
\hline
\end{tabular}

\footnotetext{
${ }^{1} \log _{10} \mathrm{SCC}=\log 10$ transformed SCC.

${ }^{2} \log _{10} \mathrm{Cdiff}=\log 10$ transformed maximum difference in electrical conductivity between quarters within cow.

${ }^{3} \mathrm{Cavg}=$ average electrical conductivity within cow.
}

six or nine clusters in the data. Degree of homogeneity and separation of clusters in the nonhierarchical cluster analysis were assessed by the R-square (sum of squares of Prin 1 between clusters divided by total sum of squares of Prin1) and the ratio between the root-meansquare standard deviation of Prin1 within clusters pooled across all clusters and the total root-meansquare standard deviation of Prin1. It was chosen to apply the 9-cluster solution, as it had the best evaluation: R-square of 0.98 (0.94 in the 6-cluster solution) and ratio of within and between root-mean-square standard deviation of 0.16 (0.24 in the 6-cluster solution). Number of observations, mean, standard deviation, and range of Prin 1 for each cluster are given in Table 5.

\section{Cluster-wise Summary}

Both the prevalences of subclinical mastitis and the incidences of clinical mastitis increased with increasing cluster number as can be seen from Figures 1 and 2 . Prevalences of subclinical mastitis and incidences of clinical mastitis were highly correlated with cluster number ( $\mathrm{r}=0.94$ to 0.96$)$ and significantly different for zero $(P<0.0001)$. The diversity of pathogens and percentage of dry quarters increased with increasing cluster number as can be seen in Table 6. Table 7 shows for each cluster, the values of all the milk parameters expressed as percentage of the average value for the healthy subset. With few exceptions, the milk parameters behaved as expected from the eigenvectors (weights) given to the original variables in the PCA with the best production results in cluster 1 and the worst in cluster 9 .

Cluster 1 contained $4.6 \%$ of the observations. Udder health was supreme, as there was no occurrence of clinical mastitis, and the prevalence of subclinical mastitis 
SLOTH ET AL.

Table 4. Eigenvalues, proportion of variation described, eigenvectors, and loadings for principal components generated by the principal component analysis based on the adjusted milk parameter rest values.

\begin{tabular}{|c|c|c|c|c|c|c|c|c|}
\hline Principal component & Prin1 & Prin2 & Prin3 & Prin 4 & Prin5 & Prin6 & Prin7 & Prin8 \\
\hline Standardized eigenvalues & 2.37 & 1.64 & 1.02 & 0.86 & 0.69 & 0.54 & 0.47 & 0.41 \\
\hline Proportion of standardized variation & 0.30 & 0.20 & 0.13 & 0.11 & 0.09 & 0.07 & 0.06 & 0.05 \\
\hline \multicolumn{9}{|l|}{ Standardized eigenvectors } \\
\hline Milk yield, rest & -0.42 & 0.24 & -0.04 & 0.11 & 0.73 & -0.27 & -0.01 & -0.37 \\
\hline Fat $\%$, rest & 0.25 & -0.53 & 0.30 & -0.06 & 0.39 & -0.26 & 0.52 & 0.27 \\
\hline Protein \%, rest & 0.33 & -0.51 & 0.08 & 0.17 & 0.25 & 0.33 & -0.52 & -0.40 \\
\hline Lactose $\%$, rest & -0.39 & -0.25 & -0.43 & 0.37 & 0.17 & 0.48 & 0.12 & 0.42 \\
\hline Citrate $\%$, rest & -0.17 & 0.16 & 0.74 & 0.60 & -0.11 & 0.07 & -0.07 & 0.15 \\
\hline $\log _{10} \mathrm{SCC}^{1}$, rest & 0.44 & 0.18 & -0.32 & 0.41 & 0.14 & -0.46 & -0.35 & 0.40 \\
\hline $\log _{10}$ Cdiff $^{2}$, rest & 0.44 & 0.27 & -0.18 & 0.41 & -0.02 & 0.23 & 0.56 & -0.40 \\
\hline Cavg, ${ }^{3}$ rest & 0.30 & 0.46 & 0.19 & -0.35 & 0.43 & 0.49 & -0.08 & 0.33 \\
\hline \multicolumn{9}{|l|}{ Loadings } \\
\hline Milk yield, rest & -0.65 & 0.31 & -0.04 & 0.11 & 0.61 & -0.20 & -0.00 & -0.23 \\
\hline Fat $\%$, rest & 0.3 & -0.67 & 0.31 & -0.06 & 0.32 & -0.19 & 0.36 & 0.17 \\
\hline Protein \%, rest & 0.5 & -0.65 & 0.09 & 0.16 & 0.21 & 0.24 & -0.36 & -0.25 \\
\hline Lactose $\%$, rest & -0.60 & -0.32 & -0.44 & 0.35 & 0.14 & 0.36 & 0.08 & 0.27 \\
\hline Citrate $\%$, rest & -0.27 & 0.21 & 0.74 & 0.56 & -0.09 & 0.05 & -0.05 & 0.09 \\
\hline $\log _{10}$ SCC, ${ }^{1}$ rest & 0.6 & 0.22 & -0.32 & 0.38 & 0.11 & -0.34 & -0.24 & 0.25 \\
\hline $\log _{10}$ Cdiff, ${ }^{2}$ rest & 0.6 & 0.34 & -0.18 & 0.38 & -0.02 & 0.17 & 0.39 & -0.26 \\
\hline Cavg, ${ }^{3}$ rest & 0.4 & 0.59 & 0.19 & -0.32 & 0.36 & 0.36 & -0.06 & 0.21 \\
\hline
\end{tabular}

${ }^{1} \log _{10} \mathrm{SCC}=\log 10$ transformed SCC.

${ }^{2} \log _{10} \mathrm{Cdiff}=\log 10$ transformed maximum difference in electrical conductivity between quarters within cow.

${ }^{3} \mathrm{Cavg}=$ Average electrical conductivity within cow

was 0.007 , corresponding to only one quarter positive with coagulase negative staphylococci out of 152 . Cows in second parity and late intervals in lactation (4 and 5) dominated the cluster. The cows had the highest relative milk yield and minimum SCC and electrical conductivity in comparison to average values in the healthy subset (Table 7).

In cluster 2 , representing $12.1 \%$ of the observations, there was no occurrence of clinical mastitis (Figure 2) but a low prevalence of subclinical mastitis (Figure 1) dominated by coagulase-negative staphylococci (Table 6). Distributions of systematic factors were generally close to the distributions in the total population, and the relative performances of the milk parameters were on average better than average healthy values.

Table 5. Numbers of cow-level observations, mean, standard deviation and range of the first principal component, Prin1, for each cluster.

\begin{tabular}{lrrll}
\hline & & \multicolumn{3}{c}{ Prin1 } \\
\cline { 3 - 5 } Cluster & $\mathrm{N}$ & Mean & $\begin{array}{l}\text { Std. } \\
\text { Dev. }\end{array}$ & Range \\
\hline 1 & 38 & -2.73 & 0.39 & -3.83 to -2.27 \\
2 & 99 & -1.75 & 0.23 & -2.23 to -1.41 \\
3 & 157 & -1.05 & 0.21 & -1.40 to -0.67 \\
4 & 188 & -0.28 & 0.23 & -0.65 to 0.13 \\
5 & 141 & 0.54 & 0.22 & 0.15 to 0.92 \\
6 & 96 & 1.30 & 0.25 & 0.93 to 1.77 \\
7 & 56 & 2.24 & 0.24 & 1.80 to 2.72 \\
8 & 34 & 3.29 & 0.34 & 2.83 to 3.98 \\
9 & 12 & 4.73 & 0.36 & 4.27 to 5.33 \\
\hline
\end{tabular}

In cluster 3 , which included $19.1 \%$ of the observations, three quarter cases of clinical mastitis were observed, and the occurrence of subclinical mastitis increased compared to the level in cluster 2 . The primary cause of subclinical mastitis was still coagulase-negative staphylococci. As in cluster 2, the distributions of systematic factors were generally close to the distributions in the total population and milk parameters still better than expected from the estimated healthy levels.

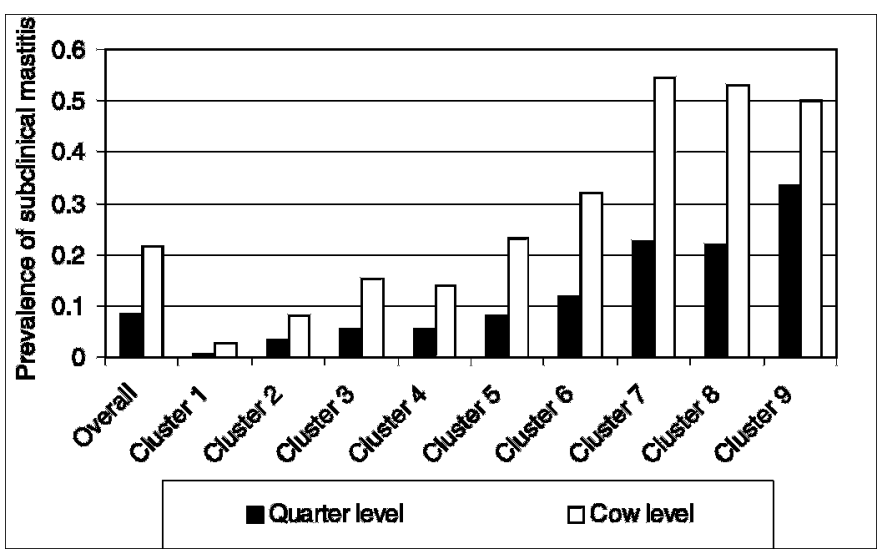

Figure 1. Overall and within cluster prevalence of subclinical mastitis calculated at quarter and cow-level based on bacteriological examination of quarter foremilk samples from the udder health surveillance scheme including samples taken out up till $30 \mathrm{~d}$ before the end of an interval in lactation. 


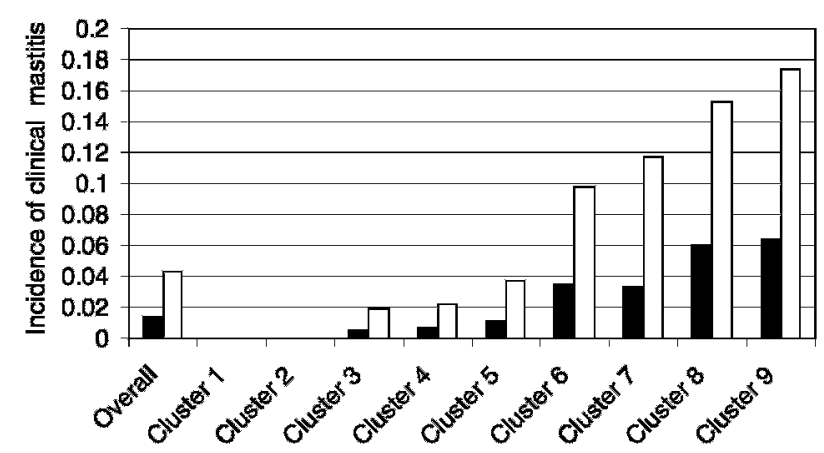

Quarter cases per 30 quarter days at risk $\square$ Cow cases per 30 cow days at risk

Figure 2. Overall and within cluster incidence of clinical mastitis calculated at quarter and cow-level as the actual rates of clinical mastitis in the $30 \mathrm{~d}$ before the end of an interval in lactation.

Cluster 4 was the largest cluster including $22.9 \%$ of the observations. The incidence of clinical mastitis was higher than in cluster 3; however, prevalence of subclinical mastitis very much resembled that in cluster 3, although with an increased proportion of Staphylococcus aureus. Distributions of systematic factors were approximately as in the total population and the milk parameters performed on average closely to average values in the healthy subset.

Cluster 5 contained $17.2 \%$ of the observations. The level of udder health in terms of occurrence of clinical and subclinical mastitis was marginally lower than the total population average. In this cluster, all possible diagnoses from the bacteriological examination of quarter foremilk samples in the udder health surveillance scheme were found. Cows on low TMR energy density, in parity 1 and second interval in lactation dominated more than expected from the total distribution of the observations. Milk yield, lactose, and citrate levels were significantly below and fat, protein, SCC, and parameters of electrical conductivity were all significantly above average values of the healthy subset.

In cluster 6 , which accounted for $11.7 \%$ of the observations, the incidence of clinical mastitis increased dramatically in comparison to the level in both cluster 5 and the total population. The prevalence of subclinical mastitis was only slightly above the level in the total population. Apart from yeasts, all possible diagnoses from the bacteriological examination of quarter foremilk samples were present. Distributions of systematic factors were approximately as in the total population. Milk parameters were all on average significantly different from the average healthy levels and more severely affected than in cluster 5 .

Cluster 7, comprising $6.8 \%$ of the observations, had a slightly lower incidence of clinical mastitis at quarterlevel compared to cluster 6 . However, the cow-level incidence increased and close to a doubling of the prevalence of subclinical mastitis was seen. The proportion of quarters subclinically infected with coagulase-negative staphylococci decreased in favor of increased occurrence of, especially, Staphylococcus aureus and dry quarters. Cows in parity 3 and third interval in lactation clearly dominated more than expected from the distribution of the observations in the total population. Except from citrate, did all the milk parameters continue to increase or decrease in the directions given by the eigenvectors in the PCA being less favorable than in cluster 6 .

Cluster 8 , representing $4.1 \%$ of the observations, closely resembled cluster 7 in the prevalence of subclinical mastitis. The proportion of quarters subclinically infected with coagulase-negative staphylococci decreased further but there was an increased occurrence of Streptococcus uberis and lactic and fecal streptococci. The incidence of clinical mastitis increased dramati-

Table 6. Overall and within cluster frequency distributions of diagnoses from bacteriological examination of quarter foremilk samples within the udder health surveillance scheme.

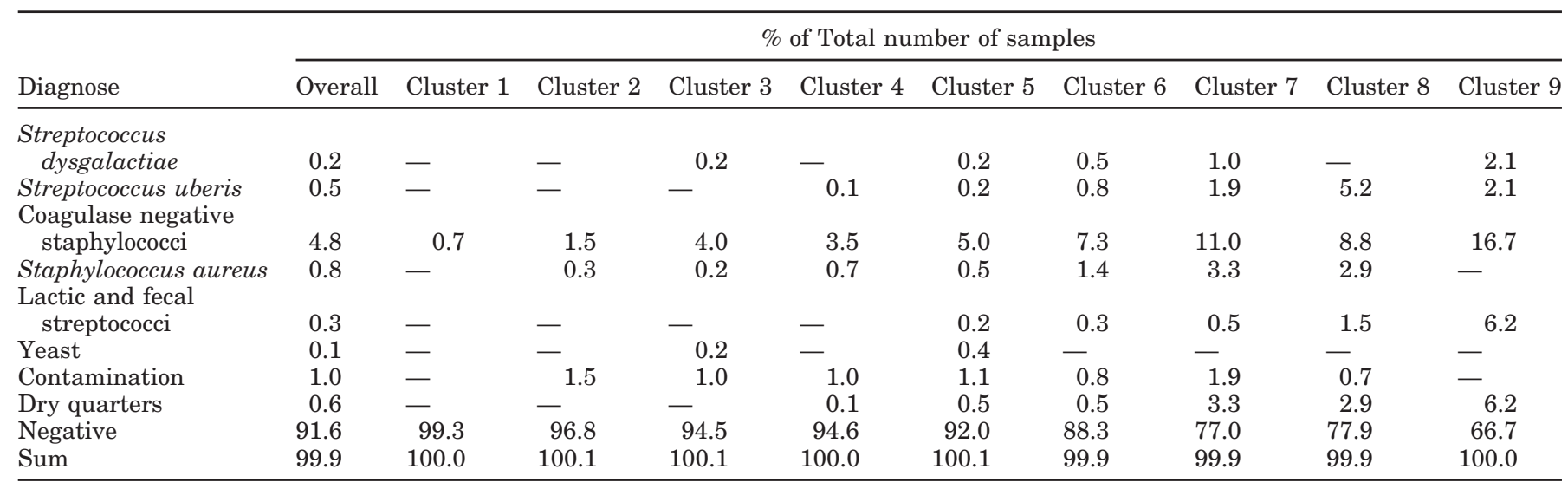


Table 7. Average observed levels of milk parameters relative to estimated healthy levels with $95 \%$ confidence limits $( \pm)$ calculated for each of the 9 clusters.

\begin{tabular}{lcrrrrrrr}
\hline & \multicolumn{7}{c}{ \% Observed of estimated healthy milk parameter level } \\
\cline { 2 - 9 } Cluster & \multicolumn{1}{c}{ Milk yield } & \multicolumn{1}{c}{ Fat \% } & \multicolumn{1}{c}{ Protein \% } & \multicolumn{1}{c}{ Lactose \% } & \multicolumn{1}{c}{ Citrate \% } & \multicolumn{1}{c}{ Log $_{10}$ SCC $^{1}$} & Log $_{10}$ Cdiff $^{2}$ & \multicolumn{1}{c}{ Cavg $^{3}$} \\
\hline 1 & $123.3 \pm 4.0$ & $91.7 \pm 2.8$ & $93.2 \pm 1.2$ & $103.3 \pm 0.7$ & $105.2 \pm 4.0$ & $77.0 \pm 5.5$ & $72.3 \pm 7.4$ & $94.2 \pm 1.9$ \\
2 & $115.7 \pm 2.9$ & $94.1 \pm 1.6$ & $95.8 \pm 1.0$ & $101.9 \pm 0.4$ & $105.5 \pm 2.5$ & $88.8 \pm 2.9$ & $82.5 \pm 5.6$ & $97.0 \pm 1.4$ \\
3 & $108.5 \pm 2.2$ & $97.5 \pm 1.4$ & $97.5 \pm 0.8$ & $100.9 \pm 0.4$ & $102.7 \pm 2.1$ & $96.9 \pm 2.8$ & $89.6 \pm 3.6$ & $98.6 \pm 1.3$ \\
4 & $102.3 \pm 1.9$ & $99.8 \pm 1.3$ & $100.5 \pm 0.7$ & $99.9 \pm 0.3$ & $100.5 \pm 2.0$ & $104.9 \pm 3.0$ & $100.6 \pm 4.8$ & $100.0 \pm 1.7$ \\
5 & $96.3 \pm 2.2$ & $102.6 \pm 1.6$ & $102.8 \pm 1.1$ & $99.4 \pm 0.4$ & $97.0 \pm 2.2$ & $115.5 \pm 4.1$ & $119.4 \pm 6.2$ & $101.9 \pm 1.3$ \\
6 & $89.9 \pm 3.3$ & $103.1 \pm 2.1$ & $103.5 \pm 1.4$ & $98.8 \pm 0.7$ & $94.1 \pm 2.2$ & $131.0 \pm 5.5$ & $133.9 \pm 8.7$ & $104.9 \pm 1.8$ \\
7 & $84.3 \pm 4.3$ & $105.2 \pm 2.2$ & $105.3 \pm 1.5$ & $97.8 \pm 0.6$ & $96.7 \pm 3.6$ & $141.7 \pm 8.1$ & $170.9 \pm 16.4$ & $106.6 \pm 2.2$ \\
8 & $79.9 \pm 6.4$ & $108.4 \pm 4.1$ & $106.5 \pm 1.9$ & $95.5 \pm 1.4$ & $93.0 \pm 4.4$ & $149.3 \pm 9.0$ & $175.6 \pm 15.9$ & $112.1 \pm 3.9$ \\
9 & $58.5 \pm 10.3$ & $104.4 \pm 5.7$ & $103.2 \pm 4.8$ & $87.9 \pm 3.2$ & $92.8 \pm 6.2$ & $158.1 \pm 22.5$ & $186.7 \pm 22.6$ & $113.5 \pm 6.0$ \\
\hline
\end{tabular}

${ }^{1} \log _{10} \mathrm{SCC}=\log _{10}$ transformed SCC.

${ }^{2} \log _{10}$ Cdiff $=\log _{10}$ transformed maximum difference in electrical conductivity between quarters within cow.

${ }^{3}$ Cavg $=$ Average electrical conductivity within cow.

cally in comparison to the level in cluster 7 . Cows on low TMR energy density, in parities 2 and older, and in first and late intervals in lactation (4 and 5) dominated more than expected from the total distribution of the observations. All the milk parameters continued to deviate further in the expected directions away from the estimated healthy levels.

In cluster 9 , including only $1.5 \%$ of the observations, the highest incidence of clinical mastitis and quarterlevel prevalence of subclinical mastitis was found. The cluster was heavily dominated by cows on low TMR energy density, in second and third parities and late intervals in lactation (4 and 5). Milk yield, lactose, citrate, SCC, and parameters of electrical conductivity showed on average the most severe response of all clusters. Fat and protein, however, moved in the opposite direction compared to their general increasing trend with cluster number including the average healthy level within their $95 \%$ confidence intervals.

\section{DISCUSSION}

The stepwise multivariate analysis of the eight milk parameters used in this study resulted in a combined measure that showed a significant relation to udder health status even though the original data came from three different breeds in different lactation stages, parity, and feed combinations. The contribution of each step in the analysis and the associated assumptions are discussed below.

\section{Multivariate Mixed Model}

The purpose of modeling the systematic factors was to adjust for their average effects in the milk parameters. A multivariate approach was used, because it provided a common model for adjustment of all eight milk parameters thus avoiding bias in any one parameter due to use of different univariate models. In addition, it reduced the number of models and covariance matrices to be fitted. Although a common model is desirable when adjusting a multivariate dataset, it may be less appropriate with respect to identifying significant effects for particular variables. Consequently, this aspect of the mixed model outcome is of less importance in the current study. The significance of the systematic effects in the final model is generally supported in the literature (Dohoo and Meek, 1982; Sheldrake et al., 1983; Kaufmann and Hagemeister, 1987; Hellander et al., 1989; Hamann and Zeconni, 1998) and agrees with univariate analyses of these data (Nielsen et al., accepted). The mixed model accounted for a substantial portion of the variance in the raw data (Table 3), especially in fat and protein percentage.

An important issue when adjusting the milk parameters for systematic effects is to avoid, as far as possible, overadjustment in which a part of the mastitis-related responses in the milk parameters is removed in the adjustment. The risk of this occurring increases the more uneven the distribution of mastitis cases is across the experimental structure. A way of avoiding this problem, used in the study, was to generate the necessary adjustment factors from analysis of a subset of observations designated as healthy. This requires the assumption that the underlying systematic variation is the same in the defined healthy and nonhealthy subsets. We believe this to be a reasonable assumption since both subsets were within the same herd and management system. A more important assumption is that the definition of "healthy" is adequate for the analysis. As can be seen from the within cluster levels of average milk parameter performances (Table 7), the fourth cluster closely resembled the estimated levels in the healthy subset although the cluster was not free of mastitis 
(Figures 1 and 2). The applied healthy definition, therefore, most probably included a mixture of entirely healthy cows, future and earlier diseased cows, and possibly a few undetected subclinically infected cows. Koldeweij et al. (1999) applied a reference population defined as no clinical mastitis within the week of testday and cow-level SCC equal to or less than 200,000 cells per milliliter in a survey addressing milk yield loss in relation to milk SCC. Rajala-Schultz et al. (1999) recommended use of premastitis levels of milk yield as reference, instead of levels in healthy cows on lactational basis when estimating the effect of clinical mastitis on cow-level milk yield. This was to avoid underestimation of the true effect of mastitis, as cows with mastitis generally yielded more milk than did their healthy herdmates. Investigation of how healthy definitions will affect the sensitivity of the final output from our analysis is planned in a separate study.

\section{Principal Components Analysis}

The main idea behind the choice of methods in this study was to combine responses in several milk parameters into one variable descriptive of cow-level udder health. The selected milk parameters in the study were affected by the three types of responses, which according to Kitchen (1981), occur in the udder during a mastitis incident. These are the animals' disease combatting response, which elicits increase in SCC, alteration in the blood-milk barrier, and impaired synthetic and secretory ability. Alteration in the blood-milk barrier occurs through damage to ductal and secretory epithelium, opening up tight junctions between secretory cells, and increased permeability of blood capillaries and has a range of effects. Changes in concentrations of $\mathrm{Na}^{+}, \mathrm{Cl}^{-}, \mathrm{K}^{+}, \mathrm{Ca}^{2+}$, and $\mathrm{Mg}^{2+}$ result in increased electrical conductivity of the milk (Kitchen, 1981). The citrate content and to some extent the lactose content in the milk will decrease because of diffusion down the concentration gradient into blood via paracellular routes (Peaker, 1975; Faulkner and Peaker, 1982). The alterations in membrane permeability also cause influx of serum proteins to the milk in higher concentrations than normal (Kitchen, 1981). Impaired synthetic and secretory activity of udder epithelial cells results in decreased casein, lactose, and fat content of the milk (Ashworth et al., 1967) and decreased milk yield. Hortet et al. (1999) and Koldeweij et al. (1999) have recently assessed milk yield losses in relation to increasing SCC. As the change in the concentration of a milk component is strongly related to the actual milk secreted by the affected gland, it will be sensitive to dilution or upconcentration depending on directions, speeds, and sizes of concomitant changes in both milk yield and the milk component itself (Schultz, 1977). Dealing with the composition of cow composite milk samples, concentration of a milk component will furthermore be influenced by cow-level number of diseased quarters as investigated for SCC in milk by Natzke et al. (1972).

Carrying out the principal component analysis on adjusted values ensured that the variability between systematic strata did not obscure differences due to within strata factors, such as udder health. Given that systematic variation was removed, it was expected that udder health effects would emerge in one of the first components. Prin 1 did indeed reflect the main consequences of mastitis (Schultz, 1977; Kitchen, 1981). It was based mainly on the contrasts between milk yield and lactose percentage vs. SCC and Cdiff. However, protein and fat percentages were given positive weights, although both casein and fat was expected to decrease with mastitis. A possible explanation could be that, to some extent, milk yield decreased more rapidly than protein and fat syntheses and, furthermore, that increases in serum protein partly compensated for decreases in casein.

Prin2 was interpreted as thin milk with a high average electrical conductivity and believed to reflect a relationship between milk solids and electrical conductivity. According to Woolford et al. (1998), fat concentration in the milk along with other milk solids modulate measurement of electrical conductivity of the base electrolyte. Hillerton and Walton (1991) found high electrical conductivity in milk from uninfected cows, which tended to have milk compositional abnormalities, especially low-fat contents. Prin3 appeared to reflect variations in the intracellular metabolism of the secretory cells in accordance with Chaiyabutr et al. (1981), Faulkner and Peaker (1982), and Kaufmann and Hagemeister (1987) addressing citrate, fatty acid, and lactose syntheses. As the loadings for SCC and Cdiff were negative, the low but positive loading for Cavg could be caused by compensatory changes in the anions and cations because of decreased lactose in order to maintain a constant osmolarity in the milk (Kaufmann and Hagemeister, 1987).

An important assumption in the principal component analysis relates to the effect of systematic factors on the correlations between milk parameters. Although the data were adjusted for average differences due to systematic effects, there could still be, in principle, different correlations within systematic factors. Such differences would, if marked, be detectable in scatter plots of successive components. As there was no evidence of this, it was assumed that there were no major differences in correlations between milk parameters due to systematic effects. 


\section{Cluster Analysis}

The cluster analysis identified nine subdivisions of Prin1. As the prevalence of subclinical mastitis and incidence of clinical mastitis increased significantly with increasing cluster number (Figures 1 and 2), there was a clear relationship between responses in the milk parameters and the udder health within the herd. This demonstrates that the technique may be able to offer a considerably better quantification of response caused by mastitis than traditionally infected and noninfected classification.

Earlier investigations have found increasing responses in milk parameters at both quarter and cowlevel with increasing severity of the mastitis. Woolford (1985) reported results from studies with identical twins, where daily milk yield was compared to measure the effect of clinical and subclinical mastitis. In those studies, milk yield fell to 82 and $85 \%$ with clinical mastitis and to $95 \%$ with subclinical mastitis. These decreases in milk yield correspond to the levels of milk yield in clusters 7 to 8 and in cluster 5 in the present study (Table 7). Ashworth et al. (1967) used quarter comparisons within cow and found decreasing fat and lactose percentages and increasing protein percentages with increasing CMT reactions. In another quarter comparison trial performed by Oshima and Fuse (1981), citrate content was found to decrease proportionally with $\mathrm{Na}$ and $\mathrm{Cl}$ difference value reflecting increased response with increased severity of subclinical mastitis.

The distributions of specific pathogens involved in subclinical mastitis within the clusters changed from primarily coagulase-negative staphylococci and contamination in the lower cluster numbers to a wider diversity of pathogens and increasing numbers of dry quarters in the higher cluster numbers. However, coagulase-negative staphylococci dominated in all the clusters. According to Pyörälä (1995), this group of pathogens is often the cause of teat infections, which usually results in a mild response in the cow. However, as persistent infections they have been found to affect milk yield negatively. Fox et al. (1985) reported a significantly higher reduction in milk yield in subclinically infected quarters with major pathogens like Staphylococcus aureus, Klebsiella sp., Escherichia coli, and Streptococcus dysgalactiae than in quarters subclinically infected with minor pathogens, such as coagulasenegative staphylococci and Corynebacterium bovis. Ward and Schultz (1972) showed that quarters without a prehistory of clinical mastitis, subclinical infections with Staphylococcus aureus and Streptococcus uberis yielded a higher SCC than subclinical infections with coagulase-negative staphylococci. However, if the quarters had a prehistory of clinical mastitis, the result was the opposite way around. Fernando et al. (1982) and Sheldrake et al. (1983) showed differences in electrical conductivity in subclinical mastitis depending on pathogens involved, major pathogens generally resulting in a greater response than minor pathogens.

Certain trends in the distributions within clusters of systematic factors were expected as some of the factors dealt with in this study have been recognized as risk factors for mastitis. Clusters 8 and 9, which had the highest incidences of clinical mastitis, were clearly dominated by cows on low TMR energy density, in second and older parities, and in first (cluster 8) and late intervals in lactation (clusters 8 and 9). This is in accordance with Sovani et al. (2000), who found a positive relation between increased negative energy balance (worst 25\%) in early lactation and the occurrence of clinical mastitis. Furthermore, they found that early mastitis $(<5 \mathrm{~d}$ postpartum) was associated with later occurrence of mastitis and that cows in second, third, and fourth parities compared to cows in parity 1 had 2 times, $>2$ times and $>4$ times greater risk of getting mastitis, respectively. The findings of Hortet et al. (1999) and Koldeweij et al. (1999) of higher milk yield losses due to increased SCC in multiparous cows compared to primiparous, indicate that parity influences the specific response in milk yield caused by subclinical mastitis. Stage of lactation may be of similar importance as Hortet et al. (1999) reported increased milk yield losses due to elevated SCC with increasing DIM for multiparous cows. These increased reductions in milk yield could be explained by a poorer udder health status in multiparous and/or at the end of lactation, due to increased exposure to possible infections and permanent glandular damage from previous infections (Hortet et al., 1999).

An important point to consider when relating health status to changes in milk parameters is the effect of previous infections on the mammary gland integrity. Examination of disease records revealed that there were some nondiseased cows (no clinical and subclinical mastitis within the 30-d period before the end of an interval in lactation) within the high cluster numbers. However, the majority of these cows had a prehistory of one or more incidents of clinical mastitis, subclinical mastitis, or both. Given these findings, it will be important to assess the effect of different definitions of udder health on the analysis prior to further application of this multivariate approach. For example, does one mastitis incident in time have comparable effect on milk parameters as several incidents in time? And even if the disease has disappeared, it may still influence milk parameters with varying short- and long-term effects. It is also likely that some confounding exists from other 
diseases than mastitis, which affect milk parameters similarly.

The perspectives for multivariate analysis of milk parameters in relation to udder health do not only include identification of suboptimal producing animals including the diseased. It gives the ability to set udder health on a continuous scale for multipurpose use, e.g., assessment of severity and duration of intramammary infections, diagnosis of recovery, strategies for treatment, and culling. However, the sensitivity of the output towards assumptions made in the analysis, particularly the effects of different definitions of healthy subset, remains to be investigated. The number and kind of milk parameters in the PCA panel and number of principal components in the cluster analysis also remain to be optimized according to availability/cost of obtaining records.

\section{CONCLUSIONS}

Application of multivariate methods in this study made it possible to conduct a combined analysis of the variation in eight cow-level milk parameters to quantify udder health. The study underlined the relationship between increasing responses in milk parameters and increasing udder health problems in terms of clinical and subclinical mastitis. Based on these findings it may be stated that udder health is not a binary phenomenon and that there is a real potential in improving description of udder health status by multivariate methods.

\section{ACKNOWLEDGMENTS}

The technical assistance of the staff at the research farm Ammitsbøl Skovgaard (Vejle, Denmark) is gratefully acknowledged. The authors thank Inger Marie Jepsen, Claus Wiese, and Tine Nellemann for skilled technical assistance in collection of samples; Leif Michael Møller, Connie Middelhede, Uffe Thorøe Christensen, and Erik Decker for their contributions in data management; Inge Riis Korsgaard and Søren Højsgaard for statistical support, and Morten Dam Rasmussen for generous comments on the manuscript.

This study was part of the MEMO project founded by the Danish Ministry of Food, Agriculture, and Fisheries and the Danish Cattle Industry via Finance Committee Cattle.

\section{REFERENCES}

Ashworth, U.S., T. L. Forster, and L. O. Luedecke. 1967. Relationship between California Mastitis Test reaction and composition of milk from opposite quarters. J. Dairy Sci. 50:1078-1082.

Chaiyabutr, N., A. Faulkner, and M. Peaker. 1981. Changes in the concentrations of the minor constituents of goat's milk during starvation and on refeeding of the lactating animal and their relationship to mammary gland metabolism. Br. J. Nutr. 45:149-157.

Cullen, G. A. 1966. Cells in milk. Vet. Bull. 36:337-346.

Dohoo, I. R., and A. H. Meek. 1982. Somatic Cell Counts in Bovine Milk. Can. Vet. J. 23:119-125.

Erskine, R. J. 2001. Mastitis control in dairy herds. Page 397-433 in Herd Health: Food Animal Production Medicine. Otto M. Radostits, ed. 3rd ed. W.B. Saunders Company, Philadelphia.

Faulkner, A., and M. Peaker. 1982. Reviews of the progress of Dairy Science: Secretion of citrate into milk. J. Dairy Res. 49:159-169.

Fernando, R. S., R. B. Rindsig, and S. L. Spahr. 1982. Electrical conductivity of milk for detection of mastitis. J. Dairy Sci. 65:659-664.

Fox, L. K., G. E. Shook, and L. H. Schultz. 1985. Factors related to milk loss in quarters with low somatic cell counts. J. Dairy Sci. 68:2100-2107.

Hamann, J., and V. Krömker. 1997. Potential of specific milk composition variables for cow health management. Livest. Prod. Sci. 48:201-208.

Hamann, J., and A. Zecconi. 1998. Evaluation of the electrical conductivity of milk as a mastitis indicator. Bulletin of the International Dairy Federation, No. 334:5-22, Brussels, Belgium.

Hellander, E., L. O. Sjaunja, and J. Schaar. 1989. Citrathaltens variation i komjölk och leverantörmjölk. Swedish University of Agricultural Sciences, Report 87, Uppsala, Sweden.

Hillerton, J. E., and A. W. Walton. 1991. Identification of subclinical mastitis with a hand-held electrical conductivity meter. Vet. Rec. 128:513-515.

Hortet, P., F. Beaudeau, H. Seegers, and C. Fourichon. 1999. Reduction in milk yield associated with somatic cell counts up to 600,000 cells/ml in French Holstein cows without clinical mastitis. Livest. Prod. Sci. 61:33-42.

IDF. 1997. Recommendations for presentation of mastitis-related data. Bull. Int. Dairy Fed., No. 321, Brussels, Belgium.

Kaufmann, W., and H. Hagemeister. 1987. Composition of milk. Page 107-171 in Dairy-Cattle Production. World Animal Science. C. Production-System Approach. H. O. Gravert, ed. Elsevier Science Publishers B. V., Amsterdam, The Netherlands.

Kitchen, B. J. 1981. Review of the progress of Dairy Science: Bovine mastitis: milk compositional changes and related diagnostic tests. J. Dairy Res. 48:167-188.

Koldeweij, E., U. Emanuelson, and L. Janson. 1999. Relation of milk production loss to milk somatic cell count. Acta Vet. Scand. 40:47-56.

Natzke, R. P., R. W. Everett, and D. S. Postle. 1972. Normal milk somatic cell counts. J. Milk Fd. Technol. 35:261-263.

Nielen, M., Y. H. Schukken, J. van de Broek, and A. Brand. 1993. Relations between on-line electrical conductivity. J. Dairy Sci. 76:2589-2596.

Nielsen, H. M., N. C. Friggens, P. Løvendahl, J. Jensen, and K. L. Ingvartsen. 2003. The influence of breed, parity and stage of lactation on lactational performance and relationship between body fatness and live weight. Livest. Prod. Sci. 79:119-133.

Oshima, M., and H. Fuse. 1981. Citric acid concentration in subclinical mastitic milk. J. Dairy Res. 48:387-392.

Peaker, M. 1975. Recent advances in the study of monovalent ion movements across the mammary epithelium: Relation to onset of lactation. J. Dairy Sci. 58:1042-1047.

Pyörälä, S. 1995. Mastitis caused by different microbes. Page 143-160 in The Bovine Udder and Mastitis. M. Sandholm, T. HonkanenBuzalski, L. Kaartinen, and S. Pyörälä, ed. University of Helsinki, Helsinki, Finland.

Rajala-Schultz, P. J., Y. T. Gröhn, C. E. McCulloch, and C. L. Guard. 1999. Effects of clinical mastitis on milk yield in dairy cows. J. Dairy Sci. 82:1213-1220.

SAS. 1999. Version 8.e. SAS Inst., Inc., Cary, NC.

Schukken, Y. H., and W. D. J. Kremer. 1996. Monitoring udder health: Objectives, materials and methods. Pages 351-360 in Herd Health and Production Management in Dairy Practice. A. Brand, J. P. T. M. Noordhuizen, and Y. H. Schukken, eds. Wageningen Pers, Wageningen, The Netherlands. 
Schultz, L. H. 1977. Somatic cells in milk-physiological aspects and relationship to amount and composition of milk. J. Food Prot. 40:125-131.

Sharma, S. 1996. Applied Multivariate Techniques. John Wiley and Sons, Inc., New York.

Sheldrake, R. F., R. J. T. Hoare, and G. D. McGregor. 1983. Lactation stage, parity, and infection affecting somatic cells, electrical conductivity, and serum albumin in milk. J. Dairy Sci. 66:542-547.

Sovani, S., C. Heuer, W. M. Van Straalen, and J. P. T. M. Noordhuizen. 2000. Disease in high producing dairy cows following post parturient negative energy balance. Pages 137-150 in Proc. Soc. Vet. Epid. Prev. Med., Edinburgh, Scotland.
Ward, G. E., and L. H. Schultz. 1972. Relationship of somatic cells in quarter milk to type of bacteria and production. J. Dairy Sci. 55:1428-1431.

Wheelock, J. V., J. A. F. Rook, F. K. Neave, and F. H. Dodd. 1966. The effect of bacterial infections of the udder on the yield and composition of cow's milk. J. Dairy Res. 33:199-216.

Woolford, M. W. 1985. The relationship between mastitis and milk yield. Kieler Milchwirtschaftliche Forschungsberichte 37:224231.

Woolford, M. W., J. H. Williamson, and H. V. Henderson. 1998. Changes in electrical conductivity and somatic cell count between milk fraction from quarters subclinically infected with particular mastitis pathogens. J. Dairy. Res. 65:187-198. 